\title{
Desequilíbrio financeiro,
}

\section{missões da universidade}

\section{e avaliação - Autorreflexão na USP ${ }^{1}$}

RICARDO TERRA I

I

NSTITUIÇÕES antigas como universidades precisam, de tempos em tempos, sofrer profundas reformas para que possam continuar a ter papel relevante na cultura, na ciência, na sociedade e no setor produtivo. Profundas mudanças sociais, políticas, culturais, científicas e nos processos produtivos também levam a grandes crises e transformações nas universidades. Em determinados períodos da história, universidades tradicionais tornaram-se praticamente irrelevantes e desapareceram ou tiveram que passar por verdadeiras revoluções. ${ }^{2} \mathrm{O}$ conservadorismo das universidades que não conseguiam acompanhar as mudanças científicas, culturais e econômicas levou a se pensar em outras formas de criação e ampliação do saber (basta ver o que aconteceu no bojo da Revolução Francesa). Há já algum tempo, com a transformação da ciência e da tecnologia em principal força produtiva ${ }^{3}$ nas sociedades contemporâneas ou, em outro diagnóstico, com o advento do que alguns chamam de sociedade do conhecimento, estamos vivendo uma enorme crise da instituição universitária.

As universidades brasileiras passam por uma situação muito difícil. Por um lado, são pressionadas pelas dificuldades financeiras e pela instabilidade política do país; por outro, têm que responder a vários desafios, como a necessária internacionalização na produção de ciência e tecnologia, e às diversas demandas locais.

Rápidas transformações tecnológicas demandam investimentos e agilidade nas mudanças das universidades para que elas possam antecipar desafios e responder às exigências prementes que a sociedade e a economia apresentam, resistindo, entretanto, ao imediatismo que os políticos procuram impor ao processo da pesquisa e reagindo, também, ao corporativismo mediocrizante. Essas atitudes urgentes se dão em um momento de esgarçamento do tecido social, das relações entre as pessoas e mesmo entre partes da instituição. Ou seja, em um quadro difícil, a Universidade tem que realizar, ao mesmo tempo, a internacionalização e cuidar dos efeitos locais. A situação exige rapidez e ousadia nas atitudes, mas a tendência atual é conservadora, de defesa das particularidades e da manutenção do status quo. Cada faculdade, cada departamento, cada curso 
de pós-graduação e, finalmente, cada professor procura manter as suas particularidades, sem levar em conta sua inserção na Universidade.

No caso específico da Universidade de São Paulo (USP), a crise tem vários aspectos e níveis: a crise da universidade vinculada às transformações da tecnologia e do capitalismo; as crises econômicas do Brasil; finalmente, o descontrole financeiro provocado por equívocos em sua administração. Pretendo neste texto apontar possíveis articulações entre algumas iniciativas que procuraram refletir sobre as crises e apontar perspectivas de mudanças.

O presente artigo é composto de duas partes: na primeira retomo alguns temas que foram se consolidando em livros recentes, de diversos autores, sobre a USP; na segunda, tento organizar uma parte do debate e pensar alguns desafios que a USP terá que continuar a enfrentar.

\section{Diagnósticos recentes da situação da USP}

A autorreflexão - a reflexão sobre a universidade na universidade - tem ocorrido de uma forma produtiva há algum tempo e sob diversas formas, em debates, artigos e livros.

\section{Universidade em Movimento}

Gostaria de comentar algumas publicações. O primeiro é o dossiê "Universidade em Movimento". "Convém chamar a atenção para alguns aspectos dessa publicação. Os artigos do dossiê provêm de um seminário sobre governança da Universidade, realizado em março de 2015, coordenado pelo professor Jacques Marcovitch, professor da FEA e ex-reitor da USP. Segundo Marcovitch, o seminário foi organizado para a "avaliação dos erros cometidos em 2013 e que ainda hoje consomem tantas energias na reparação dos danos" (Marcovitch, 2015, p.45). A crise financeira e as perdas das reservas levaram a uma rápida reação tanto na análise intelectual do fenômeno como nas necessárias e duras medidas administrativas de saneamento.

A relevância do dossiê torna-se patente pela amplitude dos aspectos tratados, não ficando apenas no campo econômico-financeiro. Com uma visão sistêmica e valorização da conformidade (compliance), Marcovitch aponta os erros cometidos, mas principalmente apresenta caminhos a serem seguidos, tanto no sentido de impedir os erros como também no sentido da boa gestão, levando em conta os valores universitários.

Os desafios para o financiamento das universidades públicas e o desequilíbrio financeiro da USP são tratados nos artigos dos professores Carlos Antonio Luque e no texto escrito por Vahan Agopyan e Rudinei Toneto Jr.. A questão da autonomia universitária e a lei de responsabilidade fiscal é desenvolvida por Nina Ranieri. As questões da excelência e da avaliação são abordadas nos artigos de José Goldenberg e Luiz Nunes. E, finalmente, Sergio Adorno (2015, p.85) amplia a noção de crise do âmbito financeiro para colocar a questão da identidade da Universidade levando em conta "seus eixos fundadores: liberda- 
de e autonomia; indissociabilidade entre ensino e pesquisa; transversalidade do conhecimento".

Uma iniciativa como essa nos lembra que a perspectiva reflexiva tem que ser constante e coletiva, o que talvez tenhamos em parte perdido. "O que nos anima", escreve Marcovitch (2015, p.50), "é a hipótese de lograr um consenso em torno de poucos temas, dispersos em livros, artigos, relatórios, projetos e cabeças". É importante o esforço conjunto que leva em conta o que já se produziu sem a ilusão de que se começa do zero. A criação de uma esfera pública universitária na USP é, assim, uma prioridade. É pelo debate que poderemos refinar o diagnóstico da Universidade e de nossa época e elaborar propostas. Como escreveu Luiz Nunes (2015, p.73),

[...] será necessário motivar a comunidade para a reforma. A USP precisa dela para desenvolver planos coletivos e conseguir chegar às primeiras filas dos rankings internacionais. Meios e oportunidades estão ao alcance de todos. Falta despertar a vontade coletiva, e aí se encontra o grande desafio, o abismo que nos separa da USP de 2034 que a sociedade deseja.

Em 2017, os textos foram republicados, com pequenas alterações, com o título Universidade em movimento. Memória de uma crise, e incluindo alguns capítulos da tese de doutorado de Alexandre Sassaki, Governança e conformidade na gestão universitária, orientada pelo professor Jacques Marcovitch e defendida em agosto de 2016 na FEA. A contribuição trazida pelos capítulos da tese é ampla e precisa. Além da análise detalhada da evolução do orçamento da USP e do ICMS de 2009 a 2014, do comprometimento dos repasses com pagamento de salários, a análise das decisões e da justificativa ou ausência de justificava das decisões são esclarecedores. Sassaki analisou as matérias sobre a Universidade publicadas pelo jornal Folha de S.Paulo, as atas das sessões do Conselho Universitário e da Comissão de orçamento e Patrimônio de 2010 a 2014.

Uma distinção importante feita por Sassaki é entre decisões com impacto pontual e as decisões com impacto plurianual. É impressionante o número de decisões sem discussão e sem fundamentação. $\mathrm{O}$ acúmulo de decisões desse tipo levou ao desastre. "Percebe-se que a Universidade carece de instrumentos de efetivo monitoramento, análise e controle de riscos (financeiros e não financeiros)", escreve Sassaki: "A comissão de Orçamento e patrimônio do Conselho Universitário, [...] tem atribuições relacionadas ao planejamento orçamentário. No entanto, sem competência expressa para monitorar a execução orçamentária ou para atuar preventivamente na identificação de riscos para o ano corrente ou para exercícios futuros" (Sassaki, 2017, p.176).

\section{Relatório de Gestão 2014 -2017}

Outro documento importante para o diagnóstico da USP e a reflexão sobre seu futuro são os seis pequenos volumes de Uma universidade em evolução. Relatório de Gestão - 2014-2017. Apesar de ser um documento oficial, um relatório da gestão 2014-2017, o texto traz uma consolidação importante de dados referentes 
às principais iniciativas promovidas em diversos níveis (reitoria, pró-reitorias, Aucani e Auspin, Conselho Universitário e outros órgãos da Universidade) e oferece um primeiro balanço das ações, articulado a uma reflexão sobre a Universidade. Assim, é mais um documento que tem que ser levado em conta na ação cooperativa de diagnóstico e planejamento de ações visando transformar a Universidade no sentido da realização de suas missões.

A crise financeira foi enfrentada de maneira a não colocar em risco a excelência e, principalmente, a autonomia da Universidade. Ao lado de medidas duras, porém necessárias, como os programas de incentivo ao desligamento voluntário (PIDV), foram tomadas medidas que reforçam a autonomia, como a Criação de uma Controladoria Geral, que é "um órgão do Conselho Universitário, com independência para apreciar criticamente a gestão da Universidade e com legitimidade para manter interlocução com os órgãos de controle externo, notadamente o Tribunal de Contas e o Ministério Público", como explicitado na página 38, volume 4 do Relatório de Gestão / 2014-2017. O desequilíbrio financeiro foi vencido, mas era necessário também evitar futuros problemas financeiros e erros administrativos. Daí a importância da criação da Controladoria e da aprovação pelo Conselho Universitário dos "Parâmetros de Sustentabilidade Econômico-financeira". Em relação à manutenção e ampliação da excelência, medidas foram tomadas em relação à valorização do ensino de graduação, da pós-graduação, da pesquisa, da abertura para a sociedade e a internacionalização.

Gostaria de ressaltar um processo que foi iniciado e que será consolidado pela nova gestão: o processo de avaliação. Uma universidade não pode atingir a excelência se não existe um efetivo sistema de avaliação de todas as suas missões. A criação da nova Comissão Permanente de Avaliação (CPA), com suas duas câmaras, e a valorização do projeto acadêmico e não apenas dos projetos científicos possibilitará que se leve em conta o ensino de graduação, de pós-graduação, a pesquisa, as atividades culturais, a transferência de tecnologia e todas a ações de abertura para a sociedade. $\mathrm{O}$ quadro institucional foi criado, mas falta a mudança cultural e a criação das rotinas específicas, daí a necessária criação e ampliação de uma esfera pública universitária que cultive a excelência.

Outro exemplo de ação que exige a continuidade é o Inova USP, o programa de internacionalização da pesquisa com laboratórios internacionais. O prédio está pronto, a tarefa agora é montar os laboratórios.

\section{Os desafios da autonomia universitária}

A esses documentos veio se juntar, em junho de 2018, o livro de Paulo Muzy e Drugowich, Os desafios da Autonomia Universitária. O livro segue as peripécias da autonomia na USP de 1989 a 2017. É uma reflexão fundamental sobre as consequências do decreto do governador Orestes Quércia de fevereiro de 1989, que estabeleceu a autonomia financeira para as universidades estaduais paulistas. A riqueza do livro é propiciada, em parte, pela metodologia utilizada: ampla pesquisa em vários jornais e revistas que publicaram matérias sobre 
a autonomia das universidades paulistas e artigos de autoridades acadêmicas e políticas; entrevistas com um grande número de acadêmicos; amplo levantamento de dados financeiros da USP; rica pesquisa bibliográfica sobre a USP e a universidade brasileira.

A combinação de editoriais de jornais com artigos de professores e jornalistas, atas do CO, comunicados do Cruesp, livros, entrevistas com os próprios gestores da USP e dados estatísticos permite reconstruir os momentos fundamentais da história da USP e permite, também, um amplo diagnóstico da Universidade.

É um livro indispensável para fundamentar um debate sólido sobre os acontecimentos dos últimos anos e para abrir pistas sobre o futuro da USP. Trata de uma gama ampla de temas organizados a partir do conceito fundamental de autonomia. Podemos entender, por exemplo, como foram formadas as ditas reservas financeiras da USP e como foram desperdiçadas. A autonomia financeira que foi posta em risco com os gastos impensados, que levou a folha de pagamentos a superar a receita recebida do Estado, é central no livro, mas ele não fica por aí. A autonomia universitária é pensada em toda sua amplitude, em relação às missões básicas da Universidade, mas também em seus aspectos jurídicos, políticos e históricos.

O terceiro capítulo ("O conceito de autonomia") retoma o desenvolvimento histórico do conceito. A autonomia foi pensada de diversas maneiras dependendo do período histórico, desde a autonomia em relação à administração das cidades até os confrontos com os príncipes e com a Igreja. A revolução humboldtiana defendendo a liberdade de pesquisa, ensino e aprendizado levou à ampliação do conceito de autonomia. O próprio Humboldt tentou conquistar a autonomia financeira quando da fundação da Universidade de Berlim em 1910, propondo ao rei a doação à universidade de terras secularizadas dos jesuítas. $\mathrm{O}$ rendimento das terras poderia assim manter a universidade (Humboldt, 2010, p.117-18). Infelizmente a proposta não foi aceita pelo rei.

Como a noção de autonomia é bastante ampla, também as medidas indicadas envolvem, além da boa gestão financeira, outros aspectos, como o poder ou a autoridade acadêmica. Uma das teses fortes do livro é que autonomia não é sinônimo de autarquia corporativista de professores, alunos ou funcionários. $\mathrm{O}$ corporativismo é um mal que deturpa e coloniza a necessária liberdade exigida pelas instituições de pesquisa e ensino superior. O livro mostra como intelectuais da USP já alertavam há muito tempo sobre os riscos do corporativismo e do populismo que assolavam a Universidade.

\section{Desafios postos a uma universidade pública estadual}

Luc Weber, um dos criadores dos "Glion Colloquium", um think tank que reúne a cada dois anos mais de vinte reitores de prestigiadas universidades de pesquisa de todo o mundo para refletir sobre os desafios atuais e pensar as demandas futuras das universidades, organiza a reflexão em seu livro L'université 
au XXIe siècle a partir de seis conceitos: (1) inovar em suas missões, (2) internacionalizar, (3) alargar as fontes de financiamento, (4) racionalizar a governança, (5) reforçar a liderança, (6) desenvolver a cultura da qualidade. Inspirado livremente pelo livro de Weber, pretendo fazer algumas considerações sobre a USP levando em conta os livros referidos na primeira parte deste texto e minhas observações pessoais.

\section{Inovar em suas missões}

A formulação de Luc Weber, "inovar em suas missões", coloca, de saída, uma visão ampla de inovação relacionada às missões da universidade (ensino, pesquisa e extensão). Uma das perspectivas é a valorização do ensino, já que, com a supervalorização da pesquisa e da pós-graduação, frequentemente, a graduação é colocada em último lugar. Os bons cursos de pós-graduação são premiados com financiamento pela Capes, os pesquisadores são valorizados com bolsas de produtividade do CNPq. A docência na graduação, por sua vez, não é beneficiada por nenhum incentivo especial. Ora, uma universidade de pesquisa tem também como missão fundamental formar profissionais de alto nível. Além da valorização do ensino, a busca pela inovação obriga a uma contínua transformação das maneiras de estruturar os cursos, levando em conta as possibilidades abertas pela informática e pelos meios audiovisuais.

A necessidade da contínua inovação na pesquisa e na extensão (ou serviços à sociedade) é mais óbvia e frequentemente tratada. A transferência de conhecimento para as políticas públicas e para o setor econômico está no cerne de diversas iniciativas, tanto nas universidades como nas agências financiadores da ciência e tecnologia. Na USP, vale ressaltar as ações da Agência de Inovação (Auspin).

Podemos também levar em conta um outro sentido menos amplo do conceito de missões da universidade. No caso que nos interessa mais imediatamente, a questão seria formulada levando em conta a especificidade da USP, ou seja, uma universidade pública estadual que faz parte dos sistemas de ensino superior, pesquisa e inovação tecnológica estadual e nacional.

Os efeitos locais de uma universidade constituem uma de suas missões fundamentais. A ciência e a técnica, sem dúvida, têm uma perspectiva por assim dizer universal, mas no planejamento dos recursos aplicados pelas universidades podem ser decisivos os estudos dos possíveis efeitos locais. Por exemplo, pesou na decisão da USP de criar um curso de Engenharia de Petróleo, em Santos, a perspectiva de extração do pré-sal e a capacidade de refino no estado de São Paulo.

A clareza em relação às missões da universidade, que estão em contínua transformação para acompanhar as transformações econômicas, políticas e culturais, será da maior importância para a análise de todos os outros aspectos. A reflexão sobre nossas universidades exige, ao mesmo tempo, o acompanhamento das transformações das melhores universidades mundiais, bem como que se levem em conta as exigências e as possibilidades locais. 
Procurei em outro texto chamar a atenção para alguns dilemas das universidades brasileiras (Terra, 2014). O projeto de uma universidade "nacional-desenvolvimentista" está completamente esgotado. Não é possível uma universidade fechada em um país tentando reproduzir internamente toda cadeia de conhecimento e produção de tecnologia. Por outro lado, a ideologia dominante da universidade de classe mundial pode se tornar apenas um modelo inalcançável e, o que é pior, deformado por uma visão gerencial meramente quantitativista chamei esse modelo de "universidade de excelência administrada". Poderíamos pensar em um modelo, digamos, "social-desenvolvimentista de universidade", que deveria ser eficaz sem cair na excelência administrada quantitativista e meramente imitadora de instituições estrangeiras. Ou seja, a reinvenção da universidade e suas novas missões devem levar em conta os efeitos locais, em um quadro democrático, enfrentando a questão das desigualdades e respondendo aos desafios sociais, políticos e econômicos.

\section{Internacionalização}

Outra exigência básica é a internacionalização. Essa exigência é mais discutida e aceita entre nós. Na USP temos a atividade contínua da Agência USP de Cooperação Acadêmica Nacional e Internacional - Aucani. Deixo para tratar dessa questão em outra oportunidade. Apenas gostaria de lembrar que em relação à internacionalização nossas decisões na aplicação dos recursos dependem também da visão que vai se consolidando sobre nossas missões e dos efeitos locais desejados.

\section{Alargar as fontes de financiamento}

As crises podem abrir possibilidades para grandes mudanças necessárias, mas sempre adiadas. A crise financeira por que passou a USP foi causada por uma confluência de fatores, alguns antigos, como a falta de regulação dos gastos. Basta lembrar que o Decreto da Autonomia sugeria um gasto de $75 \% \mathrm{com}$ a folha de pagamentos, o que não foi seguido. Outro fator adicional mais recente é a brutal queda do PIB brasileiro (após 2014), que levou à diminuição do ICMS (Muzi; Drugowich, 2018).

Mesmo com o controle da situação financeira, a situação econômica, sem grandes perspectivas de crescimento de curto prazo, coloca novos desafios para a direção da Universidade: o que cortar, o que criar ou incentivar. Antes da crise, com os recursos aumentando, a administração central podia manter os programas existentes, atender certas demandas das unidades e planejar o crescimento. Com a crise, as exigências em relação às universidades aumentam e, como os recursos não crescem, a administração central (reitoria e $\mathrm{CO}$ ), foram obrigados a ter um protagonismo maior. Em uma universidade de pesquisa, a dificuldade de decidir é sempre grande: é necessário levar em conta o que cortar e o que incentivar, visando reagir com rapidez às transformações da sociedade, da ciência e da tecnologia. Demorar a reagir é perder o bonde da história. 
No período de crescimento das receitas foi possível crescer em todos os aspectos, aumentando vários programas e atividades, cursos, apoio à permanência estudantil, inclusão, creches e hospitais. Em uma situação muito melhor que a nossa, com a crise desde 2008, mesmo em países ricos como Japão, Inglaterra e Estados Unidos, cortes foram feitos nas universidades. É desolador observar que, nesses países, as humanidades são as mais prejudicadas, devido a uma visão imediatista tecnocrática, que chamamos de modelo da excelência administrada quantitativista.

Olhando a situação da nossa prima estadual, a Uerj, podemos ver que o impensável se tornou realidade. O estado do Rio de Janeiro está deixando uma das melhores universidades brasileiras em um estado calamitoso. A aprovação pelo Conselho Universitário da USP dos Parâmetros de Sustentabilidade demonstra que há uma maioria no $\mathrm{CO}$ que pode assumir com a reitoria a direção da Universidade em épocas difíceis, mesmo com os ataques de grupos corporativistas. É muita ingenuidade ou má-fé achar que o governo do estado de São Paulo vai aumentar os gastos com as universidades estaduais em detrimento do ensino secundário, que tem uma situação muito mais precária. Sem as medidas de controle de gastos, ficaríamos próximos das dificuldades da Uerj.

Além do corporativismo sindical, há a perspectiva isolacionista das unidades. Como a ideia de universidade (um bom e velho conceito) está desgastada e fraca, o que temos são unidades que fazem seu lobby para benefício próprio, ignorando a instituição maior - os estudantes fazem seu lobby para aumentar seus privilégios (se levarmos em conta que a maioria dos estudantes brasileiros entra na fila para se endividarem pelo Fies a fim de estudar em faculdades ruins), os funcionários e professores pressionam por aumentos salariais e aumento indefinido do efetivo. Todas as pressões convergem para a direção central e aparecem no Conselho Universitário. Alguns conselheiros não têm nenhuma perspectiva universitária, apenas representam e defendem interesses corporativos de suas unidades ou de suas especialidades, outros expressam imediatamente a ideologia política dos grupelhos "organizados", ignorando sistematicamente a instituição universitária. Como disse, por enquanto, felizmente, tem sido formado uma maioria no $\mathrm{CO}$ que está tomando as medidas urgentes necessárias. Mas a partir daí, impõe-se a grande tarefa - encontrar os recursos, pensar e planejar a universidade pública estadual paulista que o século XXI exige.

O grande desafio é ampliar o financiamento das universidades estaduais para cumprir as missões que o século XXI impõe. Como em qualquer lugar do mundo, uma parte importante do financiamento da pesquisa vem necessariamente do financiamento estatal. O problema é que ele não é e não será suficiente para manter as universidades. A USP e as universidades brasileiras necessariamente têm que continuar a discussão e tomar as medidas necessárias visando a ampliação do financiamento. A pauta é grande: fundações, organizações sociais, acordos com a administração pública, acordos com empresas, elaboração de po- 
líticas públicas, trabalho junto com indústrias e cobrança de certos cursos, como os de extensão, aperfeiçoamento e mesmo certos mestrados profissionalizantes.

É possível enumerar algumas atitudes que podem caminhar no sentido de destravar os obstáculos às transformações e, mais ainda, criar um ambiente de criatividade em todos os planos, inclusive no plano institucional, onde se exige muita imaginação. Em seguida, enumero algumas delas continuando com os temas de Luc Weber referidos acima.

\section{Racionalizar a governança}

Não pretendo me alongar nesse tema fundamental. Para Luc Weber (2015, p.119) a boa governança deve se basear em três eixos: a autonomia, uma organização baseada no federalismo e uma direção forte acompanhada por um conselho inteligente e construtivo.

Quanto à autonomia, remeto ao livro de Muzy e Drugowich (2018) citado na primeira parte deste texto. No caso da perspectiva federalista, acredito que a USP se constituiu em uma federação muito frouxa de unidades, corroída em parte pelo corporativismo das unidades.

Acredito ser urgente o fortalecimento da direção central, acompanhada pelo $\mathrm{CO}$, visando a realização da Universidade como instituição com projetos ambiciosos e tendo clareza sobre suas missões. $O$ fortalecimento da direção central pode ser a contraposição necessária à tendência centrífuga, que em nome de uma curiosa noção de "autonomia" das unidades tem levado à destruição da concepção, para sermos breves, humboldtiana de universidade. Fica patente a necessidade de uma direção central (Reitoria e CO) com a agilidade necessária para responder aos desafios das transformações rápidas da economia do conhecimento.

Uma forma de acelerar as transformações seria com a escolha do reitor a partir um comitê de busca, sendo uma boa maneira de enfrentar o corporativismo e o jogo dos pequenos interesses de faculdades e departamentos.

\section{Reforçar a liderança}

Uma maneira de viabilizar e reforçar lideranças acadêmicas já existentes é o fortalecimento de uma esfera pública universitária. Ou seja, um espaço público comunicativo que facilite uma contínua autorreflexão da universidade, para falar em termos habermasianos. ${ }^{5} \mathrm{Ou}$, em termos bourdieusianos, apenas

[...] uma reflexão coletiva, capaz de mobilizar todas as forças vivas da instituição (e em particular, os pesquisadores mais ativos e inspirados, sobretudo entre os mais jovens) e todos os seus recursos (que seria preciso recensear e mobilizar e dar a conhecer a todos os membros da instituição), poderia conduzir a essa espécie de conversão coletiva que é a condição de uma verdadeira atualização [...] Tratar-se-ia de instaurar e fazer funcionar um dispositivo de discussão coletiva orientado para a invenção de novas estruturas organizacionais próprias para favorecer essa integração na diferenciação. (Bourdieu, 2003, p.65 e 69) 
Uma forte esfera pública universitária poderia incentivar os docentes a sair dos seus espaços especializados para pensar o futuro da universidade e suas relações com a sociedade e a economia. Aumentaria assim não apenas o autoconhecimento da universidade, mas também a esfera pública poderia se tornar um celeiro de novas lideranças.

A reflexão sobre a universidade enfrenta atualmente vários bloqueios, entre eles certo fechamento das unidades e cursos em si mesmos e, também, o corporativismo dos sindicatos. Um certo número de antigos colegas saiu da Adusp e certos jovens professores nem entraram. Não sei se muitos pensam como eu e acham da maior importância que a USP tenha um sindicato de professores. Se houver, acredito que temos que pensar na possibilidade de fundação de outra entidade sindical. Um sindicato onde haja uma imprensa democrática com real diversidade de opiniões, o mínimo absolutamente indispensável de assembleias presenciais, e que promoveria a reflexão realmente crítica, não a mera repetição de slogans como faz a atual e como fizeram as últimas diretorias da Adusp. Esse novo sindicato promoveria debates, seminários, congressos com bom nível intelectual e um clima condizente com o mundo acadêmico, as grandes decisões sendo tomadas por votações eletrônicas. Em suma, um novo sindicato que defenda os interesses dos professores, independentemente de suas posições políticas, já que seria um sindicato de professores e não um partido político. A especificidade de um sindicato de professores seria levada em consideração, já que que os vários níveis da administração da Universidade são dirigidos por docentes. Não estamos em uma empresa em que temos dois sindicatos, um dos operários e outro dos capitalistas. Somos todos acadêmicos. A política schmittiana do amigo contra inimigo que tem orientado as últimas gestões dos sindicatos é desastrosa e autoritária. ${ }^{6}$

Em suma, para a ampliação e consolidação de uma esfera pública universitária na USP seriam necessárias várias medidas, como um novo sindicato que criasse fóruns de discussão, mas também medidas tomadas nos vários níveis da administração, promovendo a reflexão realmente crítica e elaborando propostas para a modificação das instituições.

\section{Desenvolver uma cultura da qualidade}

A cultura da qualidade está intrinsecamente vinculada com a avaliação. Com a aprovação pelo $\mathrm{CO}$ do novo estatuto da Comissão Permanente de Avaliação (CPA), abre-se a oportunidade de a USP se repensar e se reinventar. Uma das câmaras da CPA cuida da avaliação institucional e, a outra, da avaliação dos docentes.

O novo modelo tem como central o projeto acadêmico, que leva em conta o ensino, a pesquisa e a extensão (entendida no sentido mais lato, incluindo projetos de elaboração de políticas públicas e transferência de tecnologia). O sucesso da avaliação a ser realizada pela nova CPA depende de uma profunda mudança cultural e depende também da clareza em relação aos desafios postos para uma universidade pública estadual, em São Paulo. 
O arranjo institucional do processo de avaliação possibilita um procedimento que permite articular as várias missões da universidade, das unidades, dos departamentos e a participação dos docentes. Os critérios, metas e objetivos serão definidos no processo. Não podem ser postos a priori. Dessa forma, quanto mais amplos a análise, a discussão e o estabelecimento de objetivos conjuntos, maior o sucesso na transformação dos vários níveis da universidade. Diante das exigências postas no século XXI às universidades, quais os objetivos dos departamentos, unidades e da administração central? Como se integram nesses organismos os projetos acadêmicos dos docentes individuais? Convém insistir que nos procedimentos de avaliação os critérios terão que ser imanentes aos respectivos projetos.

Convém chamar a atenção para ferramentas que já existem e estão sendo aperfeiçoadas e que auxiliam muito na avaliação, como o weR_USP. Essa ferramenta consolida dados de docentes, unidades e da Universidade.

Mais um passo relevante foi a criação, em 2018, do Escritório de Gestão de Indicadores e Desempenho Acadêmico (GEIND), que possibilitará um grande salto na gestão de dados e possibilitará o aumento da qualidade da avaliação.

Os processos avaliativos podem se fundar em uma tradição que foi construída lentamente na história da USP e que formaram uma espécie de fundo comum, que é disputado, mas que permite a reflexão conjunta, permite a comunicação, mesmo com muitos obstáculos. Chamo de plano de fundo (nossa Lebenswelt) o conjunto de dados culturais, valores e informações que compartilhamos e que possibilitam que entendamos o que o interlocutor fala. Quando algum aspecto do plano de fundo é tematizado explicitamente, provavelmente os interlocutores vão divergir, mas, de qualquer forma, é o plano de fundo que permite o diálogo e, também, a divergência.

Quando falamos em avaliação, em qualidade, em excelência, nosso plano de fundo é constituído pelas informações, valores e atitudes cristalizados, presentes nos documentos e práticas da Fapesp, CNPq, Capes, Scielo; no plano especifico da USP, nos documentos da Cert e nas listas de critérios de avaliação que foram elaborados pelas unidades para uso da Cert, nos processos de avaliação institucional já realizados, nos procedimentos de avaliação de projetos que concorrem nos vários editais das pró-reitorias ou da Aucani e daí por diante; no plano internacional, pelos vários rankings de universidades, mas, também, nos documentos relativos à avaliação individual dos docentes utilizados nas melhores universidades mundiais.

Qual o desafio atual? Rearticular a estrutura institucional da avaliação na USP para superar patologias óbvias: não é necessário nenhum diagnóstico verborrágico, ou pretensamente técnico, para perceber a necessidade de integração da avaliação docente com a avaliação das unidades, necessidade de valorizar as atividades de ensino e extensão. A centralidade do projeto de pesquisa levou à desvalorização do ensino e da extensão - daí a proposta de um projeto acadêmico e não apenas de um projeto de pesquisa científica. 
A intelecção do que é qualidade é possível, como dissemos, pelo fundo cultural comum. O desafio é a reformulação, criação de novos valores e invenção de processos avaliativos. Ora, isso será possível no processo de efetivação da avaliação proporcionado pelas novas comissões que compõem a CPA. O esforço de departamentos, unidades e reitoria necessariamente partirá daquele fundo comum e, então, será possível a criação de novos procedimentos e de novos valores, o que tornará possível a elaboração de projetos acadêmicos que contenham, de forma imanente, critérios de avaliação, o que, por sua vez, permitirá o respeito às diferenças.

No esforço de criar procedimentos e valores, podemos tomar, no quadro brasileiro, o exemplo da Fapesp, que, ao contrário de outras agências de fomento, tem se destacado na inovação dos processos avaliativos, se distanciando do mero quantitativismo. Pode-se publicar muito, mas com resultados pouco originais. É instrutivo refletir sobre as medidas que a Fapesp tem tomado em várias frentes para enfrentar os novos desafios postos à pesquisa científica e tecnológica. Por exemplo, um passo importante na rearticulação da avaliação é a atual súmula curricular, que, diferentemente do Currículo Lattes, deixa espaço para o pesquisador defender a qualidade do seu trabalho e de certa forma sugerir critérios imanentes para a análise. O docente tem um espaço onde pode chamar a atenção para a qualidade de um determinado artigo, livro ou outra forma de produção cultural ou científica e, dessa forma, indicar critérios de avaliação.

A Fapesp tem provocado mudanças de comportamento e valores com várias iniciativas como os Cepids, onde é necessário, além da pesquisa, a extensão e transferência de tecnologia.

A Universidade também elabora suas políticas, mas a tendência descentralizadora tem levado ao obscurecimento da importância das políticas centrais, sem falar no Cruesp, que colabora pouco para a reflexão sobre o sistema de ciência e tecnologia do estado de São Paulo. Os desafios postos para a Universidade são vários, e ela tem que reagir rapidamente para responder às demandas do ensino, da pesquisa e da interação com a sociedade. A USP tem a obrigação de inovar, buscando novos caminhos, ampliando os processos de avaliação das missões da universidade visando responder aos desafios atuais. Não pode apenas seguir as agências federais. Tem obrigação de estar na vanguarda, indicando caminhos para as agências federais, como já fez antes e como a Fapesp está realizando no presente.

Nesse quadro, a mudança de projeto de pesquisa para projeto acadêmico é uma proposta de um experimento que pode ampliar muito a capacidade de criatividade da universidade. Possibilita a abertura de inúmeras frentes de transformações tanto no plano das atividades acadêmicas dos docentes como, com os projetos acadêmicos dos departamentos e unidades, mudanças em todos os âmbitos da universidade. Abre-se a possibilidade de a Universidade se repensar nos próximos anos, que é o tempo necessário para a implantação das mudan- 
ças. É uma rara chance de transformação que pode resistir ao movimento em direção à excelência administrada quantitativista e resistir também às pressões corporativas "populistas". Ou mudamos logo ou perderemos a chance de ter uma universidade com ampla diversidade em um quadro democrático, noção que merece uma análise à parte. $\mathrm{O}$ fortalecimento da democracia na universidade está vinculado estreitamente ao fortalecimento do mérito, da excelência e, portanto, da avaliação, não se confundindo com voto, nem com a democracia política. A Universidade conseguirá ser mais que uma federação frouxa de unidades? O momento exige, o número de decisões da administração central aumentará tanto pela pressão em relação aos recursos como pela exigência de respostas criativas às demandas da sociedade, que se transforma rapidamente na sociedade do conhecimento.

\section{Notas}

1 Tive a oportunidade de conhecer boa parte da USP em minhas visitas a muitas unidades e a participação em debates como presidente do GT Atividade Docente e também como candidato à reitoria da USP, em 2017. Na campanha tive a ajuda fundamental de Paulo Muzy, a quem agradeço. Nas duas oportunidades fiquei impressionado com a força do corporativismo nas unidades e como a USP é apenas uma federação frouxa de unidades muito diferentes entre si tanto em qualidade como em autoconhecimento. $\mathrm{O}$ que mais me impressionou foi a ausência da valorização do que seriam os desafios para a universidade, as unidades se vendo como entidades autônomas dependendo da administração central principalmente para conseguir claros de docentes e de funcionários. Dificilmente a universidade poderá cumprir suas missões no século XXI sem profundas mudanças visando tornar-se uma real Universidade e deixar de ser apenas uma federação de unidades. Uma das medidas que propus na campanha para a reitoria foi o sistema de escolha do reitor por um comitê de busca, o que acredito ser a melhor forma de combater o corporativismo e provocar as continuas mudanças que a situação exige.

$2 \mathrm{O}$ exemplo da crise das universidades alemãs é marcante. Entre 1792 e 1818 o número de universidades de língua alemã foi reduzido pela metade: universidades como Straßburg, Köln, Bonn, Ingolstadt, Fulda, Bamberg, Altdorf, Salzburg, Frankfurt/Oder, Erfurt, Wittenberg e Münster fecharam suas portas. Cf. Mittelstrass (1994, p.71).

3 Ver, de Jürgen Habermas (2011), Técnica e ciência como ideologia.

4 O seminário, realizado em março de 2015 , foi coordenado pelos professores Jacques Marcovitch e Adalberto Fischmann, e publicados no dossiê "Universidade em movimento. Como alguns dos maiores artífices da USP veem a crise da instituição e projetam o futuro", Revista USP n.5 abr.-jun. 2015. Contribuíram para o dossiê: Jacques Marcovitch, Carlos Antonio Luque, Vahan Agopyan, Rudinei Toneto Jr., Nina Ranieri, José Goldenberg, Luiz Nunes de Oliveira e Sergio Adorno.

5 Para maiores desenvolvimentos a respeito, ver Terra (2012).

6 Essa situação não é apenas brasileira. Vale a pena citar uma passagem de Claude Allègre (1993, p.65-6): "Sabe-se, na França, o papel constante dessas organizações híbridas que são os sindicatos de funcionários. Aplicando ao setor público uma lógica desenvolvida para o setor privado e que tende a assimilar o Estado a um patrão explorador, eles 
têm a tendência a praticar com ardor um corporativismo estreito através da 'estratégia da suspeita'. [...] 'o sindicalismo do ensino superior depende inteiramente da qualidade de seus dirigentes. (que frequentemente são 'medíocres, sectários e ineficazes')”. O mais triste na USP não é apenas a estratégia da suspeição, é a criação pura e simples de fake news pela imprensa sindical.

\section{Referências}

ADORNO, S. "USP: êxito e a crise" em dossiê "Universidade em movimento [...]"; Revista USP, n.105, p.75-86, abr.-jun. 2015.

ALLEGRE, C. L'Âge des savoirs. Pour une renaissance de l'université. Paris: Gallimard, 1993.

BOURDIEU, P. Os usos sociais da ciência. São Paulo: Editora Unesp, 2003.

HABERMAS, J. Técnica e ciência como ideologia. São Paulo: Editora Unesp, 2011.

HUMBOLDT, W. von. Werke IV. Antrag auf Errichtung der Universität Berlin Juli 1809. Darmstadt: WBG, 2010.

MARCOVITCH, J. "Universidade em movimento" em dossiê "Universidade em movimento [...]". Revista USP, n.105, p.43-50, abr.-jun. 2015.

Arte, 2017.

(Org.). Universidade em movimento. Memória de uma crise. São Paulo: Com/

MARCOVITCH, J.; FISCHMANN, A. (Org.) Dossiê "Universidade em movimento [...]". Revista USP, n.105, abr.-jun. 2015.

MITTELSTRASS, J. Die unzeitgemäße Universität. Frankfurt: Suhrkamp, 1994.

MUZY, P.; DRUGOWICH, J. R. Os desafios da Autonomia Universitária. História recente da USP. Jundiaí: Paco Editorial, 2018.

NUNES, L. "Avaliação: resultados, tendências e desafios”, em dossiê "Universidade em movimento [...]”. Revista USP, n.105, p.65-70, abr.-jun. 2015.

SASSAKI, A. A crise, suas causas e seus impactos. In: MARCOVITCH, J. (Org.) Universidade em movimento. Memória de uma crise. São Paulo: Com/Arte, 2017.

TERRA, R. Pela democracia na USP. Informe FFLCH, n.69, ago.-set. 2012.

. A Universidade entre a excelência administrada e o social-desenvolvimentismo. Novos Estudos CEBR AP, n.100, nov. 2014.

Uma Universidade em evolução. Relatório de Gestão / 2014-2017. USP.

WEBER, L. L'université au XXIe siècle. Paris: Economica, 2015.

RESUMO - O presente artigo é composto de duas partes: na primeira, retomo alguns temas que foram se consolidando em diversos estudos publicados recentemente sobre a Universidade de São Paulo; na segunda, busco organizar parte desse debate e pensar alguns desafios que a USP terá que continuar a enfrentar.

PALAVRAS-CHAVE: USP, Desequilíbrio financeiro, Missões da Universidade, Avaliação. 
ABSTRACT - In the first part of this paper, I will take up some major already-consolidated themes related to recent analysis of the University of São Paulo; following that, I will present an organized outline of the present debate and future questions faced by this institution.

KEYWORDS: USP, Financial imbalance, Missions of the university, Evaluation.

Ricardo Terra é professor titular de Teoria das Ciências Humanas na Universidade de São Paulo (USP), pesquisador do Centro Brasileiro de Análise e Planejamento (Cebrap) e bolsista de produtividade em pesquisa do CNPq (IA). @ - ricardoterrausp@gmail.com https://orcid.org/0000-0002-5084-6704

Recebido em 15.6.2018 e aceito em 15.10.2018.

I Faculdade de Filosofia, Letras e Ciências Humanas, Universidade de São Paulo, São Paulo, São Paulo, Brasil. 
